\title{
Extensional rheology, cellular structure, mechanical behavior relationships in HMS PP/montmorillonite foams with similar densities
}

\author{
Ester Laguna-Gutierrez $^{1}$ - Alberto Lopez-Gil ${ }^{2}$ - Cristina Saiz-Arroyo ${ }^{2}$. \\ Rob Van Hooghten ${ }^{3}$ - Paula Moldenaers ${ }^{3}$ - Miguel Angel Rodriguez-Perez ${ }^{1}$
}

Received: 14 March 2016 / Accepted: 11 October 2016/Published online: 28 November 2016

(C) Springer Science+Business Media Dordrecht 2016

\begin{abstract}
The main goal of this work is to analyze the relationships between the extensional rheological behavior of solid nanocomposites based on high melt strength polypropylene (HMS PP) and montmorillonites (MMT) and the cellular structure and mechanical properties of foams produced from these materials. For this purpose two systems have been analyzed. The first one incorporates organomodified MMT and a compatibilizer and the second system contains natural clays and is produced without the compatibilizer. Results indicate that the extensional rheological behavior of both materials is completely different. The strain hardening of the polymer containing organomodified clays decreases as the clay content increases. As a consequence, the open cell content of this material increases with the clay content and hence, the mechanical properties get worse. However, in the materials produced with natural clays this relationship is not so clear. While no changes are detected in the extensional rheological behavior by adding these particles, the nano-filled materials show an open cell structure, opposite to the closed cell structure of the pure polymer, which is caused by the fact of having particle agglomerates with a size larger than the thickness of the cell walls and a poor compatibility between the clays and the polymer.
\end{abstract}

Ester Laguna-Gutierrez

ester.laguna@fmc.uva.es

1 Cellular Materials Laboratory (CellMat), Condensed Matter Physics Department, University of Valladolid, Paseo de Belen, 7, 47011 Valladolid, Spain

2 CellMat Technologies, CTTA (building), Paseo de Belen 9A, 47011 Valladolid, Spain

3 Department of Chemical Engineering, KU Leuven, Celestijnenlaan 200F, B 3001 Heverlee, Leuven, Belgium
Keywords Extensional rheology · Polymer foams · Nanocomposites $\cdot$ Structure-property relations . Polypropylene

\section{Introduction}

Common linear polypropylene (PP) has many desirable properties such as good temperature stability, good chemical resistance, high melting temperature, high tensile modulus and the capability of static load bearing [1]. These beneficial properties have permitted to use PP in many different applications. However, its linear structure leads to poor processability in processes involving melt stretching, such as extrusion coating, film blowing, thermoforming and foaming [2]. A way to improve the polymer melt strength is to incorporate long chain branches (LCB) because the PPs with LCB have a pronounced strain hardening, which is closely related to an improvement of the polymer melt strength [3]. In a previous work, different blends of a linear PP and a high melt strength PP (HMS PP) were analyzed with the aim of understanding how the extensional rheological behavior of the polymeric matrix affected the cellular structure and mechanical properties of foamed materials produced with the same density [4]. Both linear PP and blends rich in linear PP showed a low strain hardening. This low strain hardening led to a rupture of the cell walls under the extensional forces occurring during cell growth. As a result, the final foam had an elevated content of open cells, cells with large sizes and cellular structures very heterogeneous, which harmed their mechanical properties.

However, in spite of using a HMS PP to produce the foamed materials, the loss of mechanical properties when the PP is foamed at relatively low densities is very strong [5]. One approach to solve this problem consists of using nanoparticles as they can improve the overall properties of 
the foam by acting at two levels. On the one hand, nanoparticles improve the morphology and properties of the solid polymeric matrix comprising the cell walls and on the other hand, they enhance the cellular structure. Among all the possible nanoparticles those based on layered silicates, like montmorillonites (MMT), have been used in this work because they have been widely investigated, these clays are easily available and they can also be processed by employing common processing routes.

When nanoparticles are added to the polymeric matrix, many properties can be improved. Several authors have proved that MMT reinforce the polymeric matrix and therefore, they improve its mechanical properties [6-9]. Moreover, when the polymer is filled with nanoclays there are also improvements in the thermal stability as well as in the barrier and flame retardancy properties [10-12].

However, not only improvements in the physical properties of the polymeric nanocomposites are obtained. The rheological properties of these nanocomposites indicate that the polymer morphology is also affected by nanoparticles. Both linear and non-linear shear rheological properties are very sensitive to changes in the particular nanoscale and mesoscale structure [13]. Furthermore, several authors have proved that the introduction of nanoparticles can also increase the melt strength of the common linear PPs or induce strain hardening to the melt [14-17]. However, while the effects of these nanoparticles on the rheological behavior of common linear PPs have been widely investigated, as far as the author knowledge, there are no many works that analyze these effects on a HMS PP. Only two papers have been found. Bhattacharya et al. worked with HMS PP/organomodified clay nanocomposites containing different amounts of clays. They showed that all the polymers (pure polymer and nanocomposites) displayed strain hardening. Moreover, they obtained that the strain hardening was more pronounced in the polymeric nanocomposites than in the neat polymer [18]. Su et al. determined the melt strength and the apparent elongational viscosity from the Rheotens data. They obtained that the melt strength of the nanocomposites was lower than that of the unfilled polymer. In general they found that the melt strength decreased as the clay content increased. Moreover, the same behavior was followed by the apparent elongational viscosity [19]. The results obtained in these two papers are contradictory which might be an indicative of the need of a more thorough study of the rheological behavior of HMS PP/clay nanocomposites.

As mentioned above, nanoparticles not only improve the overall properties of the foamed materials by improving the polymeric matrix properties, they also contribute to this overall improvement by optimizing the cellular structure. Several works have demonstrated that the incorporation of nanoparticles leads to foams with higher cell densities, smaller cell sizes and more homogeneous cellular structures [17, 20-22]. On the one hand, nanoparticles are highly effective cell nucleating agents and they can also increase the cell nucleation rate [17, 20-22]. On the other hand, nanoparticles can reduce or even suppress cell coalescence $[17,21,22]$. As it was indicated above, the presence of nanoparticles can effectively increase the melt strength of the linear PPs and hence, improve their foamability. Nevertheless, this result is not so obvious in foams produced with HMS PP based nanocomposites as the effect that the nanoparticles have on the rheological behavior of this matrix is still not well understood (see previous paragraph).

The improvements obtained in both the solid polymeric matrix and the cellular structure are greatly affected by the degrees of filler exfoliation and dispersion achieved during the mixing process as well as by the compatibilization degree between the particles and the polymer [23]. A fully dispersed and stable state will lead to optimal properties whereas the presence of particle agglomerates or a low compatibility between the particles and the polymeric matrix can lead to a poor material performance, in some cases, even lower than that of the virgin polymeric matrix [24]. It is for this reason that the number of works dealing with the structure of the clays in the solid composites is very high. They typically analyze the effects of using non-organomodified and organomodified MMT as well as the effects of the initial interlayer spacing and the clay content [25-27]. In addition, the influence of adding or not a compatibilizer and the effects in the clay structure of the amount and type of compatibilizer have been traditionally analyzed [28-30]. Finally, the effect that the production process, required to produce the solid nanocomposites, has on the clay morphology has also been carefully studied [30, 31]. All these works are mainly focused on understanding the clay structure of linear PP/MMT solid nanocomposites. However, the number of papers that study the degree of intercalation/ exfoliation of layered composites produced with a HMS PP is limited $[18,19]$. In the same way, very few works are focused on studying the structure that the particles present after the foaming process, which is also fundamental to understand the properties of the foamed materials [21, 32].

Taking into account these ideas, in this work the effect of adding layered clays into a HMS PP polymeric matrix is studied. Particularly, the effects that these particles induce on the extensional rheological behavior of the non-foamed materials as well as on the cellular structure (cell nucleation and cell coalescence) and mechanical properties of the foamed materials are deeply investigated. This study aims at establishing a relationship between extensional rheology, cellular structure and mechanical properties of HMS PP/MMT based cellular materials. As it was previously shown, in the unfilled polymers the extensional rheology is a very useful tool to analyze and understand the cellular structure and mechanical properties exhibited by the cellular materials; however, in the filled materials this relationship is still not well-defined. To meet 
these objectives, cellular materials with the same density and with different clay contents have been produced and analyzed. Moreover, due to the importance of both the degree of exfoliation/dispersion and the degree of compatibilization, this study is performed in two completely different systems. The first system comprises a material produced using natural (non organomodified) clays and without a compatibilizer and the second system refers to a material including both organomodified clays and a compatibilizer.

In a previous work developed by the authors of this publication it is possible to find a detailed study about the morphology of the different solid and foamed composites employed in this work [33].

\section{Experimental section}

\section{Materials}

A branched HMS PP supplied by Borealis (PP Daploy WB $135 \mathrm{HMS}$ ) with a melt flow index (MFI) of $0.24 \mathrm{~g} \mathrm{~min}^{-1}$ $\left(230^{\circ} \mathrm{C} / 2.16 \mathrm{~kg}\right)$ was used in this study. The HMS PP density at room temperature is $905 \mathrm{~kg} \mathrm{~m}^{-3}$. Two types of commercial clays were employed as fillers for the PP composite preparation. A non-organomodified MMT, Cloisite ${ }^{\circledR} \mathrm{Na}+(\mathrm{Na}+)$ supplied by Southern Clay Products with a density of $2860 \mathrm{~kg} \mathrm{~m}^{-3}$ and a MMT organomodified with a quaternary ammonium salt, Cloisite $\AA 20 \mathrm{~A}(\mathrm{C} 20 \mathrm{~A})$ also supplied by Southern Clay Products, with a density of $1770 \mathrm{~kg} \mathrm{~m}^{-3}$. A maleic anhydride modified homopolymer polypropylene (PP-MA), Polybond 3200, supplied by Chemtura with a MFI of $11.5 \mathrm{~g} \mathrm{~min}^{-1}\left(190^{\circ} \mathrm{C} / 2.16 \mathrm{~kg}\right)$ was used as a chemical compatibilizer between the polymeric matrix and the organomodified clays.

Antioxidants Irgafos 168 and Irganox 1010 (from Ciba) were also used in order to prevent the thermal degradation of the polymers.

The foaming step was performed using a chemical blowing agent, azodicarbonamide (ADC) Lanxess Porofor M-C1 with a density of $1650 \mathrm{~kg} \mathrm{~m}^{-3}$ and an average particle size of $3.9 \pm 0.6 \mu \mathrm{m}$.

\section{Composite preparation}

Two types of solid materials were produced. The first one contains the blowing agent and it was used to produce the cellular materials. The second one, without the blowing agent, was employed for the rheological characterization and for the tensile tests. Moreover, solid composites containing the two different types of clays were also prepared. The first system is a polymeric composite in which the clay intercalation and the clay compatibilization with the polymeric matrix are not favorable. To produce this composite the polymeric matrix was blended with non-organomodified (natural) clays $(\mathrm{Na}+)$, without using a compatibilizer. On the other hand, in the second system, the clay intercalation was favored by using organomodified clays. The interlayer spacing of these clays is larger than that of the natural clays and the interaction between the clay platelets and the polymer is also better. Moreover, PP-MA was also used as a compatibilizer between the polar particles and the non-polar polymeric matrix. The steps followed to produce the different polymeric composites are described below.

In a first step, all the raw materials were vacuum dried at $50{ }^{\circ} \mathrm{C}$ for twelve hours. The two polymer/clay systems were produced in a different way.

With regards to the composites produced with the $\mathrm{Na}+$ first, the natural clays and the HMS PP were meltcompounded using a co-rotating twin screw extruder Collin $\mathrm{ZK} 25 \mathrm{~T}$ with a $\mathrm{L} / \mathrm{D}$ of 24 . The rotational speed was $50 \mathrm{rpm}$ and the melt temperature was $200{ }^{\circ} \mathrm{C}$. Composites containing three different contents of clays $(2.5,5$ and $7.5 \mathrm{wt} \%)$ were produced in this first extrusion step. Moreover, $0.1 \mathrm{wt} \%$ of antioxidants were also added to the formulation (Irgafos 168 in a proportion of $0.08 \mathrm{wt} \%$ and Irganox $1010 \mathrm{in}$ a proportion of $0.02 \mathrm{wt} \%$ ). Second, these materials were blended with $2 \mathrm{wt} \%$ of the blowing agent (ADC). In this second extrusion step the rotational speed was $120 \mathrm{rpm}$ and the melt temperature was $155^{\circ} \mathrm{C}$, which is well below the decomposition temperature of the blowing agent. Finally, a third extrusion of these materials was performed, under the same conditions as the second extrusion, with the aim of having the ADC homogeneously distributed along the material. The whole process was conducted in the same extruder. The same extrusion process, which involves a total of three extrusion cycles, was used to produce the solid composites without the blowing agent. Both materials were subjected to the same extrusion process with the aim of analyzing the rheological behavior in a material having the same thermo-mechanical history as the material used for foaming.

With regards to the composites produced with the $\mathrm{C} 20 \mathrm{~A}$ first, a masterbatch containing the C20A clays and the compatibilizer (PP-MA) in the same proportion (1:1) was produced. A rotational speed of $50 \mathrm{rpm}$ was employed and the melt temperature was $200{ }^{\circ} \mathrm{C}$. Composites with the desired clay contents $(2.5,5$ and $7.5 \mathrm{wt} \%)$ were then prepared by diluting, under these same extrusion conditions, the masterbatch in the HMS PP. In this point the antioxidants were also added to the different blends. Then, the composites were melt-blended with the blowing agent, using the same extrusion conditions as those employed with the composites containing $\mathrm{Na}+$. Again the same extrusion process was used to produce the composites without the blowing agent, for the rheological characterization.

The extrusion process used with the polymer containing the natural clays was also employed with the pure HMS PP, with the aim of using this material as a reference. Moreover, the 
effect that the number of extrusion cycles has on the extensional rheological properties of the pure HMS PP is also studied in order to analyze the importance of comparing materials with the same thermo-mechanical histories. For this purpose, the extensional rheological behavior of the HMS PP is measured after a first extrusion cycle (HMS PP-1) and after a total of three extrusion cycles (HMS PP-3).

The solid materials produced are summarized in Table 1. The nomenclature includes the content and type of particles employed and the total amount of extrusion cycles to which the material is subjected. To denote the solid composites, containing the blowing agent, which were subsequently foamed, the word "Foam" has been added at the beginning of the corresponding nomenclatures. It was not possible to produce the foamed material containing $7.5 \mathrm{wt} \%$ of $\mathrm{C} 20 \mathrm{~A}$ with the same density as the other cellular materials and due to this, this material has not been included in Table 1 .

\section{Foaming process}

The foaming process selected to produce the cellular materials was Improved Compression Molding (ICM). In this process the pellets containing the blowing agent are placed in a mold which is afterwards positioned in a hot-plate press. An initial pressure is applied to the system (41.5 bars) while it is heated until the foaming temperature $\left(200^{\circ} \mathrm{C}\right)$, which is higher than the decomposition temperature of the blowing agent. After a certain time (approximately $15 \mathrm{~min}$ ), when the blowing agent is fully decomposed, the pressure of the press is released allowing the polymer to expand until the desired ratio. Finally, the mold is introduced in cold water to cool-down the sample and hence, stabilizing the cellular structure as fast as possible [34]. The peculiarity of this foaming system is that the mold used is a self-expandable mold that allows controlling the material density by mechanical means and therefore, the foam density is independent of the formulation chosen. In this work the materials were produced with a density of $180 \mathrm{~kg} \mathrm{~m}^{-3}$. The fact of having similar densities for all the foamed materials allows an easier comparison between materials produced with different formulations. Foamed samples were discs with $150 \mathrm{~mm}$ in diameter and $10 \mathrm{~mm}$ in thickness. The works of Saiz-Arroyo et al. show a more detailed description of the ICM technique [35-37].

\section{Samples characterization}

$X$-ray diffraction $(X R D)$

XRD measurements were performed in order to analyze the structure of the layered clays. A Bruker D8 Discover A25 diffractometer with $\mathrm{Cu}-\mathrm{K} \alpha$ radiation of wavelength $0.154 \mathrm{~nm}$ was used. The diffraction spectrum was obtained over a $2 \theta$ range of $0-30^{\circ}$.

To perform the XRD measurements of the solid composites, solid precursors with a thickness of $0.5 \mathrm{~mm}$ produced by compression molding at a temperature of $220^{\circ} \mathrm{C}$ and with a pressure of 21.8 bars were used. These measurements were also performed in the clays as received and in the foamed composites.
Table 1 Summary of the formulations produced with the pure HMS PP and the different composites

\begin{tabular}{|c|c|c|c|c|c|c|c|}
\hline Sample name & $\begin{array}{l}\text { HMS PP } \\
(\mathrm{wt} \%)\end{array}$ & $\begin{array}{l}\text { PP-MA } \\
\text { (wt } \%)\end{array}$ & $\begin{array}{l}\text { Antioxidants } \\
\text { (wt\%) }\end{array}$ & $\mathrm{Na}+(\mathrm{wt} \%)$ & $\begin{array}{l}\mathrm{C} 20 \mathrm{~A} \\
(\mathrm{wt} \%)\end{array}$ & $\begin{array}{l}\mathrm{ADC} \\
\text { (wt\%) }\end{array}$ & $\begin{array}{l}\text { Number of } \\
\text { extrusion } \\
\text { cycles }\end{array}$ \\
\hline $2.5 \mathrm{Na}+-3$ & 97.4 & 0 & 0.1 & 2.5 & 0 & 0 & 3 \\
\hline $5 \mathrm{Na}+-3$ & 94.9 & 0 & 0.1 & 5.0 & 0 & 0 & 3 \\
\hline $7.5 \mathrm{Na}+-3$ & 92.4 & 0 & 0.1 & 7.5 & 0 & 0 & 3 \\
\hline $2.5 \mathrm{C} 20 \mathrm{~A}-3$ & 94.9 & 2.5 & 0.1 & 0 & 2.5 & 0 & 3 \\
\hline 5 C20A-3 & 89.9 & 5.0 & 0.1 & 0 & 5.0 & 0 & 3 \\
\hline $7.5 \mathrm{C} 20 \mathrm{~A}-3$ & 84.9 & 7.5 & 0.1 & 0 & 7.5 & 0 & 3 \\
\hline HMS PP-1 & 99.9 & 0 & 0.1 & 0 & 0 & 0 & 1 \\
\hline HMS PP-3 & 99.9 & 0 & 0.1 & 0 & 0 & 0 & 3 \\
\hline $\begin{array}{c}\text { Foam-2.5 } \\
\text { Na+-3 }\end{array}$ & 95.4 & 0 & 0.1 & 2.5 & 0 & 2 & 3 \\
\hline $\begin{array}{l}\text { Foam-5 } \\
\qquad \mathrm{Na}+-3\end{array}$ & 93.0 & 0 & 0.1 & 4.9 & 0 & 2 & 3 \\
\hline $\begin{array}{c}\text { Foam-7.5 } \\
\text { Na+-3 }\end{array}$ & 90.5 & 0 & 0.1 & 7.4 & 0 & 2 & 3 \\
\hline $\begin{array}{l}\text { Foam- } 2.5 \\
\text { C20A-3 }\end{array}$ & 92.9 & 2.5 & 0.1 & 0 & 2.5 & 2 & 3 \\
\hline $\begin{array}{l}\text { Foam-5 } \\
\text { C20A-3 }\end{array}$ & 88.1 & 4.9 & 0.1 & 0 & 4.9 & 2 & 3 \\
\hline $\begin{array}{l}\text { Foam-HMS } \\
\text { PP-3 }\end{array}$ & 97.9 & 0 & 0.1 & 0 & 0 & 2 & 3 \\
\hline
\end{tabular}




\section{Extensional rheological behavior}

The transient extensional viscosity of the pure HMS PPs, subjected to different extrusion cycles, as well as that of the composites prepared with the two types of clays was measured using a strain controlled rheometer (Ares-2 K from TA Instruments) with the extensional viscosity fixture (EVF). In this geometry two cylinders are used to wind-up the sample. One cylinder is rotating and the other one is measuring the force. In order to wind-up the sample equally on both sides, the rotating cylinder moves on a circular orbit around the force-measuring cylinder while this is rotating around its own axis at the same time. All the experiments were made at a temperature of $200^{\circ} \mathrm{C}$ (this is the same temperature at which the foaming process was performed). To perform the rheological tests, rectangular solid samples, with dimensions of $20 \mathrm{~mm} \times 10 \mathrm{~mm} \times 0.5 \mathrm{~mm}(\mathrm{~L} \times \mathrm{W} \times \mathrm{T})$, fabricated by compression molding at a temperature of $220^{\circ} \mathrm{C}$ and a pressure of 21.8 bars were employed.

The measurement protocol used considered first, a prestretch in order to compensate the thermal expansion of the sample when it was heated up from room temperature. Then, when the pre-stretch was finished, the sample was kept for $30 \mathrm{~s}$ at a constant temperature $\left(200{ }^{\circ} \mathrm{C}\right)$ without applying any stress. Finally, after this relaxation time, the experiment took place. Measurements were performed at a Hencky strain rate of $1 \mathrm{~s}^{-1}$ and the maximum Hencky strain applied was 3 for all the different materials.

\section{Density}

The density of the solid materials $\left(\rho_{s}\right)$ was determined using a gas pycnometer (Accupyc II 1340 from Micromeritics). The density of the cellular materials $\left(\rho_{c m}\right)$ was determined by using the geometric method; that is, by dividing the weight of each specimen by its corresponding volume (ASTM standard D1622-08). The samples used were cubes with dimensions of $20 \mathrm{~mm} \times 20 \mathrm{~mm} \times 10 \mathrm{~mm}(\mathrm{~L} \mathrm{x} \mathrm{W} \mathrm{x} \mathrm{T)} \mathrm{cut} \mathrm{from} \mathrm{the} \mathrm{samples}$ produced by ICM.

\section{Open cell content}

The open cell content $(O C)$ of the foamed materials was determined according to the ASTM Standard D6226-10 using a gas pycnometer Accupyc II 1340 from Micromeritics. Once again, the samples employed were cubes with dimensions of $20 \mathrm{~mm} \times 20 \mathrm{~mm} \times 10 \mathrm{~mm}(\mathrm{~L} \mathrm{x} \mathrm{W} \mathrm{x} \mathrm{T)}$.

Equation (1) was used to determine $O C$, according to the mentioned ASTM Standard:

$$
O C(\%)=100\left(\frac{V_{\text {sample }}-V_{p y c}}{V_{\text {sample }} \cdot p}\right)
$$

where $V_{\text {sample }}$ is the geometrical volume of the sample, $V_{p y c}$ is the volume measured by the gas pycnometer and $p$ is the sample porosity calculated as $\left(1-\frac{\rho_{c m}}{\rho_{s}}\right)$.

\section{Structural characterization}

Scanning Electron Microscopy (SEM) was used to analyze the cellular structure and also to quantify the cell size distribution, the average cell size $(\Phi)$, the cell density $\left(N_{V}\right)$, and the standard deviation coefficient of the cell size distribution relative to the cell size $(S D C / \Phi)$. For this purpose, the obtained micrographs were analyzed using an image processing tool based on the software Image J/Fiji [38].

Samples were cooled using liquid nitrogen to cut them without modifying their structure; then, they were vacuum coated with a thin layer of gold to make them conductive. A Jeol JSM-820 scanning electron microscope was used to observe the samples morphology.

The average cell size $(\Phi)$ is the mean cell diameter in three dimensions, which is defined as indicated in Eq. (2).

$\Phi=\sum_{i=1}^{n} \frac{\Phi^{i}}{n}$

where $n$ is the number of counted cells and $\Phi^{i}$ is the threedimensional cell size of the cell $i$.

$S D C / \Phi$ has been calculated according to Eq. (3) $[36,39]$.

$\frac{S D C}{\Phi}=\frac{1}{\Phi} \sqrt{\sum_{i=1}^{n} \frac{\left(\Phi^{i}-\Phi\right)^{2}}{n-1}}$

$S D C / \Phi$ gives information related to the width of the cell size distribution. A low value of $S D C / \Phi$ indicates a narrow and hence, a homogeneous cell size distribution where all cells have a size close to the average value.

The cell density $\left(N_{V}\right)$ has been defined as the number of cells per unit volume of the solid. The following expression (Eq. (4)) has been used to calculate the cell density. More details about the theoretical method that allows obtaining this parameter can be found in the work of Pinto et al. [38].

$N_{V}=\frac{6}{\pi \Phi^{3}}\left(\frac{\rho_{s}}{\rho_{c m}}-1\right)$

Moreover, the solid composites containing natural clays were also analyzed to measure the size of the particle agglomerates in a microscopic scale. For this purpose, an electron scanning microscope model Quanta $200 \mathrm{~F}$ from FEI was used. A backscattered electron detector and low vacuum conditions were employed to obtain the SEM micrographs. These conditions allow distinguishing clearly the particles and the polymer, which facilitates the subsequent image analysis. To 
measure the size of the agglomerates the software Image $\mathrm{J} /$ Fifi was employed. The micrographs were binarized and it was assumed that the particles were ellipses. The major axis of the ellipse was used to give an approximate value of the size of the clay agglomerates $\left(\Phi_{\mathrm{Na}^{+}}\right)$. These measurements have been performed in at least two micrographs of each solid material, obtained from different regions of the solid composite. The same microscope was employed to obtain high magnification micrographs from the foamed materials which were used to measure the thickness of the cell walls $\left(\delta_{C W}\right)$. The thickness of each cell wall was measured in three different regions of the wall. Moreover, approximately 10 cell walls per material were analyzed. Once again the quantitative analysis was performed employing the software Image J/Fifi.

\section{Mechanical tests}

An Instron Machine (model 5.500R6025) was used to perform the tensile tests in five different samples of each solid composite (without containing the blowing agent). A strain rate of $0.5 \mathrm{~mm} \mathrm{~min}^{-1}$ was employed to measure the tensile modulus $\left(E_{s}\right)$, which was calculated as the slope of the initial zone of the stress-strain curve. The tensile experiments were performed according to the standards ISO 527/1 and 2. The samples were conditioned under controlled atmosphere: $50 \%$ relative humidity and $23{ }^{\circ} \mathrm{C}$, following the standard ISO 291 . The samples for the tensile test were fabricated by compression molding at a temperature of $220^{\circ} \mathrm{C}$ and with a pressure of 21.8 bars.

The same machine was used to determine the mechanical properties in compression of the different cellular materials. Stress $(\sigma)$-strain $(\varepsilon)$ curves were obtained at room temperature and at a strain rate of $10 \mathrm{~mm} \mathrm{~min}^{-1}$. The maximum static strain was $75 \%$ for all the experiments. The compression experiments were performed according to the procedure described in the standard ASTM D1621. Samples were prisms with dimensions of $20 \mathrm{~mm} \times 20 \mathrm{~mm} \times 10 \mathrm{~mm}$ (length $\mathrm{x}$ width $\mathrm{x}$ thickness) machined from the cellular materials produced by ICM. The compression tests were performed in four different specimens of the same foamed sample and always in a direction parallel to the growing/expansion direction (thickness direction). Two parameters were obtained from these experiments: elastic modulus $\left(E_{c m}\right)$ and collapse stress $\left(\sigma_{c}\right)$ which was taken as the intersection between a parallel line to the stress-strain response at low strains and a parallel line to the plateau region of the stress-strain curve.

The experimental techniques employed in this study are detailed in other works [40-42].

\section{Results and discussion}

\section{Polymeric composites morphology}

As mentioned in the introduction, significant enhancements in the properties of a polymeric matrix can be achieved by introducing nanoparticles. However, all these potential improvements are greatly conditioned by the degrees of filler intercalation and dispersion achieved during the mixing process. In order to assess the quality of the exfoliation and/or intercalation of nanoclays in the matrix, the X-Ray diffraction technique was used. Diffraction patterns were obtained for a diffraction angle varying between $2 \theta=0-30^{\circ}$. In this range of diffraction angles, clays show a characteristic diffraction peak corresponding to the (001) plane. Figure 1 shows the angles at which this peak appears, which are not the same in the composites containing natural clays and in those containing organomodified clays. It was decided to show only this particular range of diffraction angles to observe better how this peak varies from one material to another.

Figure 1a shows that the peaks of the solid composites containing natural clays appear at higher diffraction angles than that of the natural clays as received. In the case of the foamed materials this peaks are shifted to diffraction angles lower than the one corresponding to the natural clays as received. The behavior of the composites containing organomodified clays is slightly different. The diffraction peaks of both the solid and the foamed composites containing
Fig. 1 XRD curves of the different HMS PP based composites (solid and foamed materials). a XRD curves of the pure $\mathrm{Na}+$ together with that of the solid and foamed $\mathrm{Na}+$ composites. b XRD curves of the pure $\mathrm{C} 20 \mathrm{~A}$ together with that of the solid and foamed $\mathrm{C} 20 \mathrm{~A}$ composites
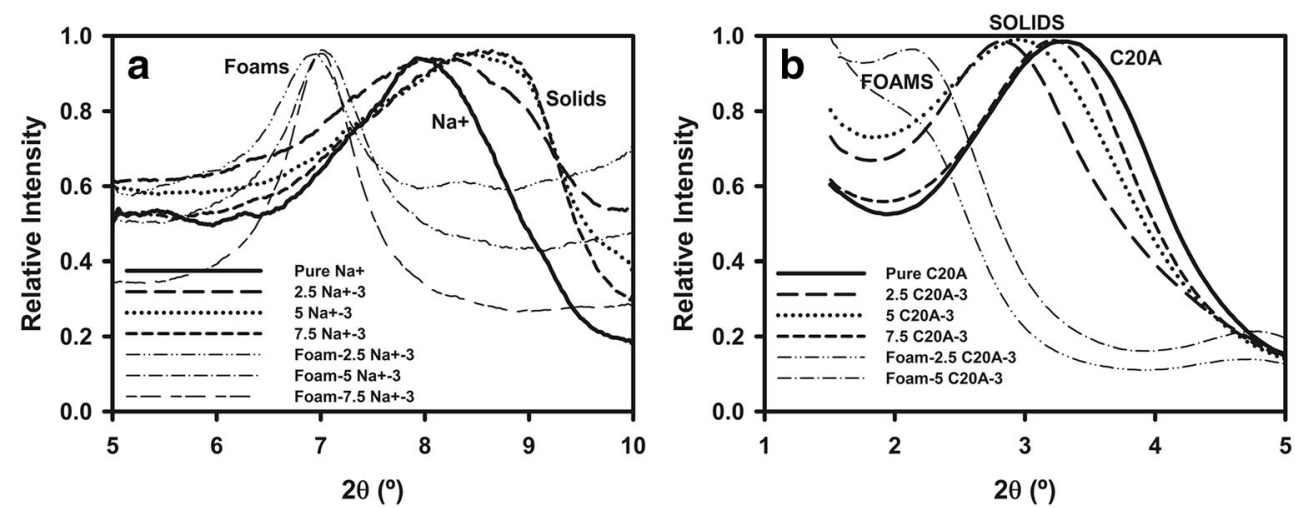
C20A appear at diffraction angles lower than that of the organomodified particles. To better understand this behavior the Bragg's law has been used. This law allows determining the clays interlayer spacing from the diffraction peak corresponding to the (001) plane (Eq. (5)) [43]:

$\lambda=2 d \sin (\theta)$

where $\lambda$ is the wavelength and $\theta$ is the diffraction angle.

The interlayer spacing values obtained from the XRD results are shown in Fig. 2. This distance has been calculated for the solid and the foamed composites and for the clays as received.

Figure 2a shows that independently of the clay content, the interlayer spacing of the natural clays as received is always higher than the interlayer spacing that the clays show after being blended with the polymer. However, in the composites produced with the organomodified clays, the interlayer spacing is larger in the clays comprising the composite than in the clays as received (Fig. 2b). These results clearly indicate that the effect that the extrusion process has on the clay intercalation depends on the type of particle employed. The extrusion process has a negative effect in the natural clays because this process induces a further agglomeration of the natural particles. Nevertheless, the same process induces a separation of the clay platelets in the organomodified particles giving as a result a more intercalated structure. During the melt extrusion process the polymer is able to separate the organomodified clay platelets due to two main reasons. On the one hand, the large initial interlayer distance presented by the C20A clays favors the penetration of the polymer into the clay gallery. On the other hand, the combination of organomodified particles and a compatibilizer (PP-MA) promotes the adhesion between the clays and the polymer. Consequently, the forces that the polymer exerts on the clay agglomerates are higher, which makes easier their intercalation with the polymeric matrix.

In addition, these results show that regardless of the type of particle the interlayer spacing decreases as the clay content increases. When the clay content increases the interaction between the clays also increases and therefore, their intercalation becomes more complicated.

Regarding the foamed materials, in the two types of composites an increase in the interlayer distance is produced after the foaming process. In the foamed material the interlayer distance decreases as the clay content increases just as it happened in the solid composites. Figure 2 also shows that the increase in the interlayer distance obtained after the foaming process is higher in the composites containing organomodified clays (1.4 times) than in those produced with the natural clays (1.2 times). The large interlayer spacing of the organomodified clays and the use of a compatibilizer might be also facilitating a further clay intercalation during the foaming process. As there is no external forces (like shear) associated to the foaming process that could help the polymer macromolecules to diffuse into the clay gaps, the increase in the interlayer spacing could be due to the expansion that the composite suffers during the foaming process. This expansion could be inducing a physical separation of the particles and consequently an increase in the interlayer spacing.

\section{Extensional rheological behavior}

Before going into details with the analysis of the solid composites it is important to analyze the effect that the extrusion process has on the extensional rheological behavior of the pure HMS PP. This effect has been studied in order to analyze the importance of comparing materials subjected to the same thermo-mechanical history. Figure 3 shows the variation of the extensional rheological behavior with the number of extrusion cycles. Figure 3 a shows the transient extensional viscosity of the pure HMS PP after one (HMS PP-1) and three (HMS PP-3) extrusion cycles.

In the two materials a phenomenon known as strain hardening, which is related to a rapid increase in the viscosity at high times (or strains), takes place [44]. However, when the number of extrusion cycles increases the slope of the curves, in the region of strain hardening, decreases. For a more quantitative
Fig. 2 Interlayer spacing of the different HMS PP based composites (solid and foamed materials). a Interlayer spacing of the pure $\mathrm{Na}+$ together with that of the solid and foamed $\mathrm{Na}+$ composites. b Interlayer spacing of the pure $\mathrm{C} 20 \mathrm{~A}$ together with that of the solid and foamed C20A composites

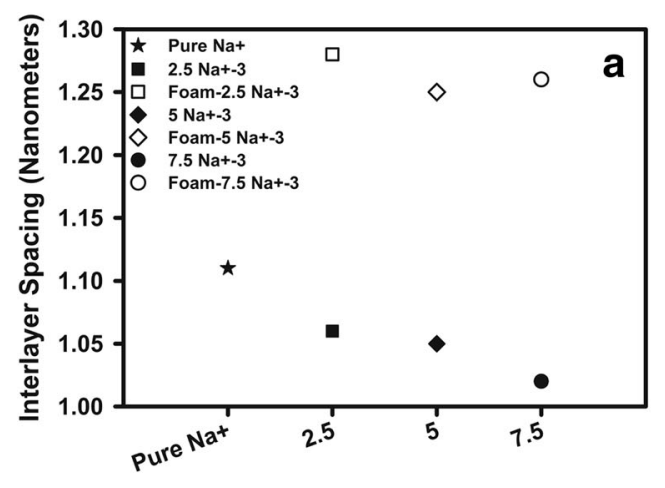

Clay Content (wt\%)

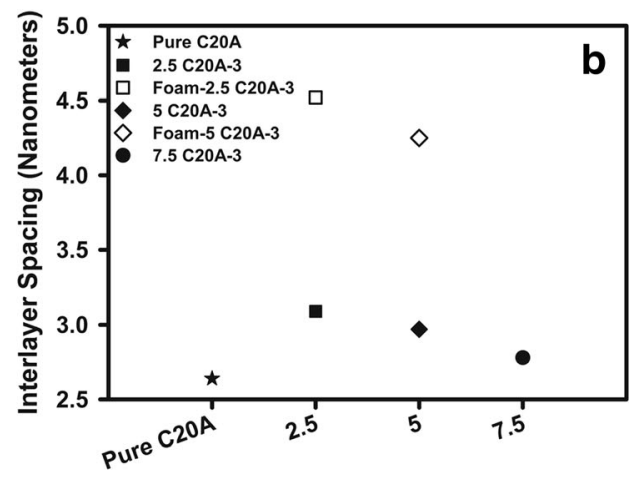

Clay Content (wt \%) 
Fig. 3 Extensional rheological behavior of the pure HMS PP after one and three extrusion cycles. a Extensional viscosity vs. time measured at a Hencky strain rate of $1 \mathrm{~s}^{-1}$. b Strain hardening coefficient calculated for a time of $3 \mathrm{~s}$ and for a Hencky strain rate of $1 \mathrm{~s}^{-1}$
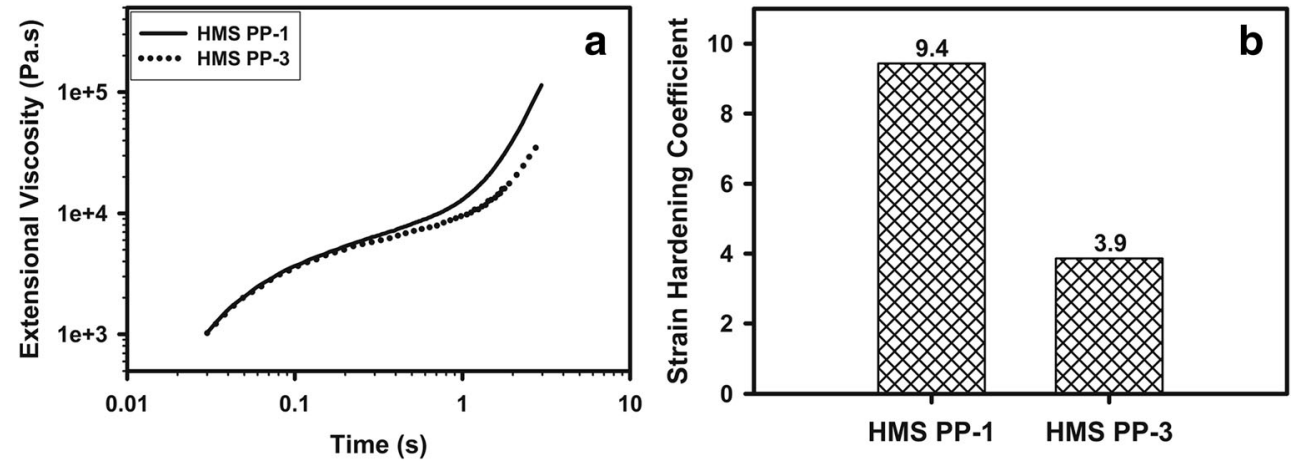

estimation of the strain hardening effect the so-called strain hardening coefficient $(S)$ was determined according to Eq. (6),

$S=\frac{\eta_{E}^{+}\left(t, \dot{\varepsilon}_{0}\right)}{\eta_{E 0}^{+}(t)}$

where $\eta_{E}^{+}\left(t, \varepsilon_{0}\right)$ is the transient extensional viscosity as a function of time and Hencky strain rate and $\eta_{E 0}^{+}(t)$ is the transient extensional viscosity in the linear viscoelastic regime, which can be determined in two different but equivalent ways: as three times the transient shear viscosity growth curve at very low shear rates or by extrapolating the superimposed portion of the curves for different elongation rates $[45,46]$. This coefficient has been determined for a time of $3 \mathrm{~s}$ and for a Hencky strain rate of $1 \mathrm{~s}^{-1}$. With this coefficient it is possible to quantify the magnitude of the strain hardening phenomenon. The results obtained are shown in Fig. 3b. The strain hardening decreases approximately 2.4 times as the number of extrusion cycles increases from one to three. However, not only changes in $S$ are detected. The MFI increases from a value of $0.45 \mathrm{~g} \mathrm{~min}^{-1}$ $\left(230^{\circ} \mathrm{C} / 2.16 \mathrm{~kg}\right)$ for the HMS PP-1 to a value of $0.69 \mathrm{~g} \mathrm{~min}^{-1}$ $\left(230^{\circ} \mathrm{C} / 2.16 \mathrm{~kg}\right.$ ) for the HMS PP-3. These changes indicate that during the extrusion process the polymer is being somehow degraded. The viscosity reduction, which is also related to a reduction of the molecular weight, together with the decrease in $S$ could be indicating a possible reduction either in the content of branched components and/or in the length of the branched chains.
Due to the significant changes that the polymeric matrix suffers when it is subjected to different extrusion cycles, the extensional viscosity measurements should be performed in a material with the same thermo-mechanical history as the material (or formulation) that will be subsequently foamed. Thereby, the extensional rheological behavior may be related to the cellular structure and mechanical properties of the foamed materials. Moreover, to analyze the changes produced in the extensional rheological properties by the fact of adding particles to a pure polymeric matrix both the polymeric matrix and the polymeric composite should have the same thermomechanical history.

The extensional viscosity of the HMS PP has been compared to that of the different composites produced with the two types of clays. All the materials have the same thermo-mechanical history ( 3 extrusion cycles). Results are shown in Fig. 4.

Figure $4 \mathrm{a}$ indicates that no significant changes are produced in the extensional rheological behavior of the pure polymeric matrix by adding natural clays. Only a slight increase in the viscosity and a small decrease of the slope in the strain hardening region are detected. In addition, these changes are independent of the clay content. XRD results showed that these particles were completely agglomerated. Therefore, it was not possible to get a percolated network structure with the concentrations of particles used in this work [33]. When the particles are agglomerated and poorly dispersed their aspect ratios are very low and therefore, they do not induce significant changes in the polymeric matrix properties. With
Fig. 4 Extensional rheological behavior of the different polymeric composites. a Composites produced with the natural clays $(\mathrm{Na}+)$. $\mathbf{b}$ Composites produced with the organomodified clays (C20A)
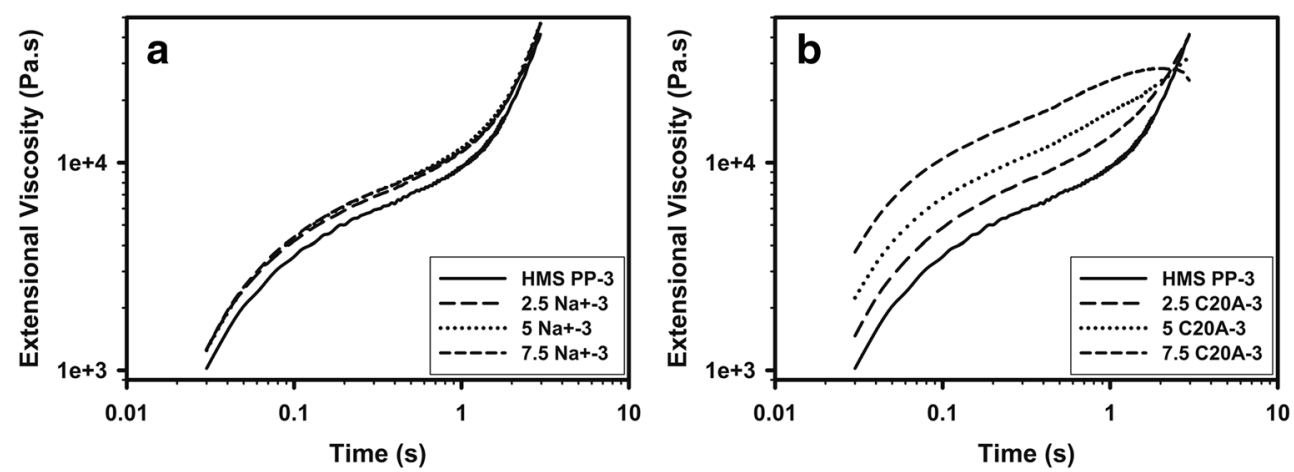
the $\mathrm{C} 20 \mathrm{~A}$ clays the changes produced in the rheological properties are very meaningful as Fig. $4 \mathrm{~b}$ indicates. In these composites as the clay content increases, a substantial increase in the viscosity occurs while the strain hardening decreases dramatically. In fact, the material with the highest clay content shows the so-called strain softening property since a decrease in the viscosity is detected at high Hencky strains [47]. In these composites, in which the interlayer spacing of the clays was higher, an intercalated structure was achieved. In a previous work it was obtained a percolation threshold of $1 \%$ for these composites [33]. The aspect ratio of these clays is larger than that of the natural clays and therefore, the formation of a percolated network structure becomes favored. When this clay network is obtained the properties of the composite are substantially affected by the presence of the particles.

As with the pure HMS PP, $S$ has also been calculated and the obtained results are summarized in Table 2.

While $S$ mildly decreases in the $\mathrm{Na}+$ composites an abrupt reduction of this coefficient is obtained by increasing the $\mathrm{C} 20 \mathrm{~A}$ content. Two possible options have been considered to explain this behavior. On the one hand, it has been considered the influence caused by the linear structure of the PP-MA used as compatibilizer. When a HMS PP is blended with a linear PP a reduction in the strain hardening occurs and this reduction depends on the ratio of linear PP and HMS PP employed [48]. However, the low amounts of PP-MA used in this work cannot explain the large changes produced in $S$. Therefore, other phenomena should be considered. Several authors have found that the strain hardening can be strongly decreased by the presence of particles [49-53]. These authors have reported that particles suppress the large deformation of the matrix polymer chains around them. In other words, the region in which elongational flow exists is decreased by the existence of particles. These particles are partially converting the extensional flow in the surrounding polymer into shear flow. Consequently the particles can interfere with the occurrence of the strain hardening phenomenon.

Table 2 Strain hardening coefficient of the different polymeric composites

\begin{tabular}{ll}
\hline Sample name & Strain hardening coefficient \\
\hline HMS PP-3 & 3.9 \\
$2.5 \mathrm{Na}+-3$ & 3.8 \\
$5 \mathrm{Na}+-3$ & 3.6 \\
$7.5 \mathrm{Na}+-3$ & 3.4 \\
$2.5 \mathrm{C} 20 \mathrm{~A}-3$ & 2.8 \\
$5 \mathrm{C} 20 \mathrm{~A}-3$ & 1.7 \\
$7.5 \mathrm{C} 20 \mathrm{~A}-3$ & 0.9 \\
\hline
\end{tabular}

\section{Cellular materials density and expansion ratio}

The density of the different foamed materials was measured, as indicated in the experimental section, and the results are summarized in Table 3. The expansion ratio $(E R)$ reached by each type of material has also been calculated according to Eq. (7) and the obtained values are also included in Table 3.

$E R=\frac{\rho_{s}}{\rho_{c m}}$

The foaming process (ICM) employed allows the production of cellular materials with a density and an $E R$ very similar regardless of the formulation used to generate them. However, the density of the cellular material containing $5 \mathrm{wt} \%$ of C20A is slightly higher than that of the rest of materials and hence, the expansion reached is also slightly lower. The strain hardening coefficient of this composite is very low; consequently, the polymeric composite is not capable of withstanding the induced stretching during the foaming process. As a result, the cell walls can easily break and the foam is not able to retain the gas during the expansion process making difficult to obtain the desired expansion ratio [54]. With the composite containing $7.5 \mathrm{wt} \%$ of organomodified clays it was not possible to produce a foam with the desired density because this material did not show strain hardening and therefore, a full collapse of the cellular structure was promoted.

\section{Open cell content}

The open cell content of the different cellular materials has also been measured. The influence that the amount of open cells has on the properties of different polymeric materials has been widely investigated. In general, high open cell contents lead to poor mechanical properties, low thermal insulation, good acoustic absorption and low dimensional stability [55-57]. Figure 5 shows the open cell content results. They have been represented together with the values of $S$ obtained for the different composites with the aim of determining if a relationship between both parameters can be established.

Figure 5a shows the open cell content of the composites containing natural clays. In these materials there is not a clear relationship between $S$ and the open cell content. While $S$ of the pure HMS PP and the different composites is the same and it remains almost unaffected by the increase in the particles concentration, important changes are detected in the open cell content when the particles are added to the polymeric matrix. In addition, it is observed that the open cell content is not affected by the clay concentration. In fact, the open cell content increases from a value of $16 \%$ to a value of $90 \%$ just by the fact of adding $\mathrm{Na}+$. That means that by adding nonorganomodified MMT it is possible to switch from a closed 
Table 3 Cellular materials density and expansion ratio

\begin{tabular}{lllll}
\hline Sample name & Density $\left(\mathrm{kg} \mathrm{m}^{-3}\right)$ & Standard deviation $\left(\mathrm{kg} \mathrm{m}^{-3}\right)$ & Expansion ratio & $\begin{array}{c}\text { Standard } \\
\text { deviation }\end{array}$ \\
\hline Foam-HMS PP-3 & 179.8 & 0.8 & 5.00 & 0.02 \\
Foam-2.5 Na+-3 & 179.5 & 0.8 & 5.04 & 0.02 \\
Foam-5 Na+-3 & 182.5 & 1.3 & 5.01 & 0.04 \\
Foam-7.5 Na+-3 & 181.6 & 1.4 & 5.11 & 0.04 \\
Foam-2.5 C20A-3 & 180.9 & 0.5 & 5.05 & 0.01 \\
Foam-5 C20A-3 & 188.5 & 0.8 & 4.90 & 0.02 \\
\hline
\end{tabular}

cell structure to an open cell structure. In general, it could be said that this is not the expected behavior. When a low-density cellular material is produced the polymeric matrix is subjected to high elongational forces during the expansion process. As a consequence, the cell walls become thinner and they can easily break. If the polymeric matrix shows strain hardening an increase in the viscosity is produced at high strains hindering the rupture of the cell walls and giving as a result foams with low open cell contents. This expected behavior is observed in the composites produced with the organomodified clays $(\mathrm{C} 20 \mathrm{~A})$ in which an increase in the open cell content is obtained when the strain hardening coefficient decreases (Fig. 5b).

The most important difference detected between the two composites is their morphology. While the $\mathrm{Na}+$ clays are agglomerated an intercalated structure was achieved with the organomodified (C20A) particles. This dissimilarity could be the reason behind the differences found in the behavior of both composites. When the particles are agglomerated they lose their laminar shape. Therefore, it is more complicated to accommodate the particles in the cell walls and they can contribute to produce a rupture of these cell walls when the size of the clay aggregates is larger than the cell wall thickness. Therefore, if the size of the clay aggregates found in the $\mathrm{Na}+$ composites is greater or of the same order of magnitude as the cell wall thickness, these aggregates could be causing the rupture of the cell walls and thus, promoting the cell opening. To prove this, the size of these aggregates was obtained from the SEM micrographs taken from the solid composites (Fig. 6a) and in addition, the cell wall thickness of the $\mathrm{Na}+$ composites was determined from the SEM micrographs, in this case, of the foamed materials (Fig. 6b). Only the results obtained for the intermediate content of natural clays (5 wt $\%$ ) are depicted in Fig. 6, since similar conclusions were obtained for the other clay contents. The micrographs reveal on the one hand, the presence of large agglomerates of particles in the solid and the foamed composites and on the other hand, that the particles are placed in both the cell edges and the cell walls.

A quantitative analysis of the SEM micrographs was performed. The three different composites showed cell walls with and average thickness of around $15 \mu \mathrm{m}$. However, these wall thicknesses are very heterogeneous with values ranging from $0.5 \mu \mathrm{m}$ to $60 \mu \mathrm{m}$. In addition, the cell wall thickness distribution (Fig. 6c) indicates that most of the cell walls have a thickness of approximately $5 \mu \mathrm{m}$. Taking into account this value, the number of agglomerates with a size higher than $5 \mu \mathrm{m}$ has been measured in the three solid composites. In the material produced with $2.5 \mathrm{wt} \%$ of $\mathrm{Na}+, 10 \pm 5 \%$ of the total amount of particles have sizes larger than $5 \mu \mathrm{m}$. This value becomes $12 \pm 2 \%$ in the composite produced with $5 \mathrm{wt} \%$ of $\mathrm{Na}+$ and $8.4 \pm 0.2 \%$ in the composite containing $7.5 \mathrm{wt} \%$ of $\mathrm{Na}+$. Taking this result into account, it can be concluded that the amount of particles with a size larger or similar than the cell wall thickness is really significant and therefore, they will be enough to produce an opening of the cell walls of these materials.

Another reason that could be explaining this behavior is the poor compatibility between the natural particles and the
Fig. 5 Correlation between strain hardening coefficient and open cell content. a Composites produced with the natural clays $(\mathrm{Na}+)$. b Composites produced with the organomodified clays (C20A)
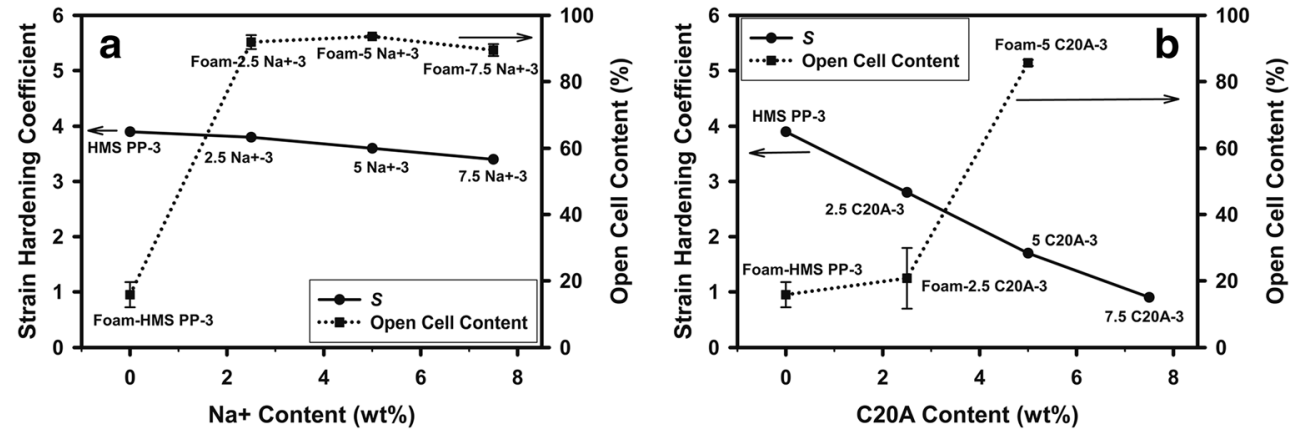

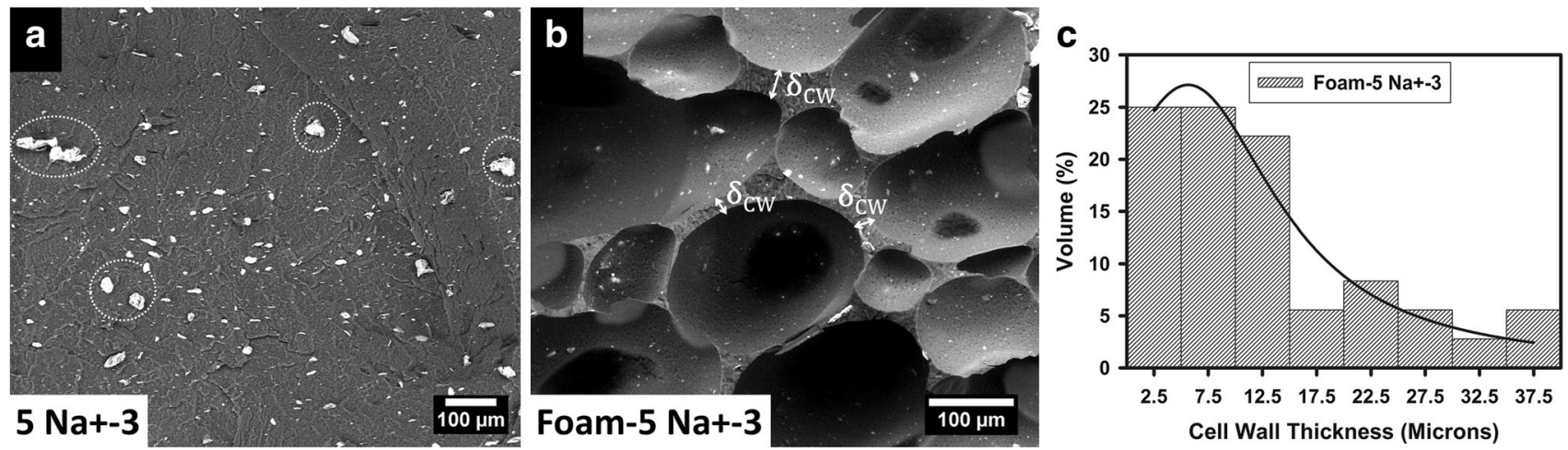

Fig. 6 a SEM micrograph of the solid composite used to measure the size of the clay aggregates (5 Na+-3). b SEM micrograph of the foamed material employed to measure the cell wall thickness (Foam-5Na+-3). c Cell wall thickness distribution for the Foam-5Na+-3

polymer matrix, since as it was indicated before this system does not contain a compatibilizer agent. When the polymeric material expands and consequently the cell wall thickness is reduced, the interphase between the particle and the polymer, which exists due to the poor compatibility between both materials, becomes a weak point where the cell wall rupture could be favored.

Therefore, in these particular materials, the extensional rheology cannot be easily related to the open cell content because, there are other phenomena which are taking place simultaneously. In the range of Hencky strains in which the measurements were performed, no differences between the materials were found. The thickness of the sample used in the extensional rheological test is too large to notice the real effect of the particles in the cell walls.

\section{Cellular structure}

SEM micrographs of the foams produced with both the pure HMS PP and the different PP based composites can be observed in Fig. 7.

Several conclusions can be extracted from the qualitative observation of these micrographs. The foam produced with the pure polymer shows the most homogeneous cellular structure. Nevertheless, pores with larger sizes are detected when natural clays are added to the polymer. The same happens when organomodified clays are added to the polymeric matrix although, the differences found in the cell sizes are not as significant as with the natural clays. The cell size distribution is analyzed in detail in Fig. 8 where the histograms obtained from the numerical analysis of these cellular structures are represented.
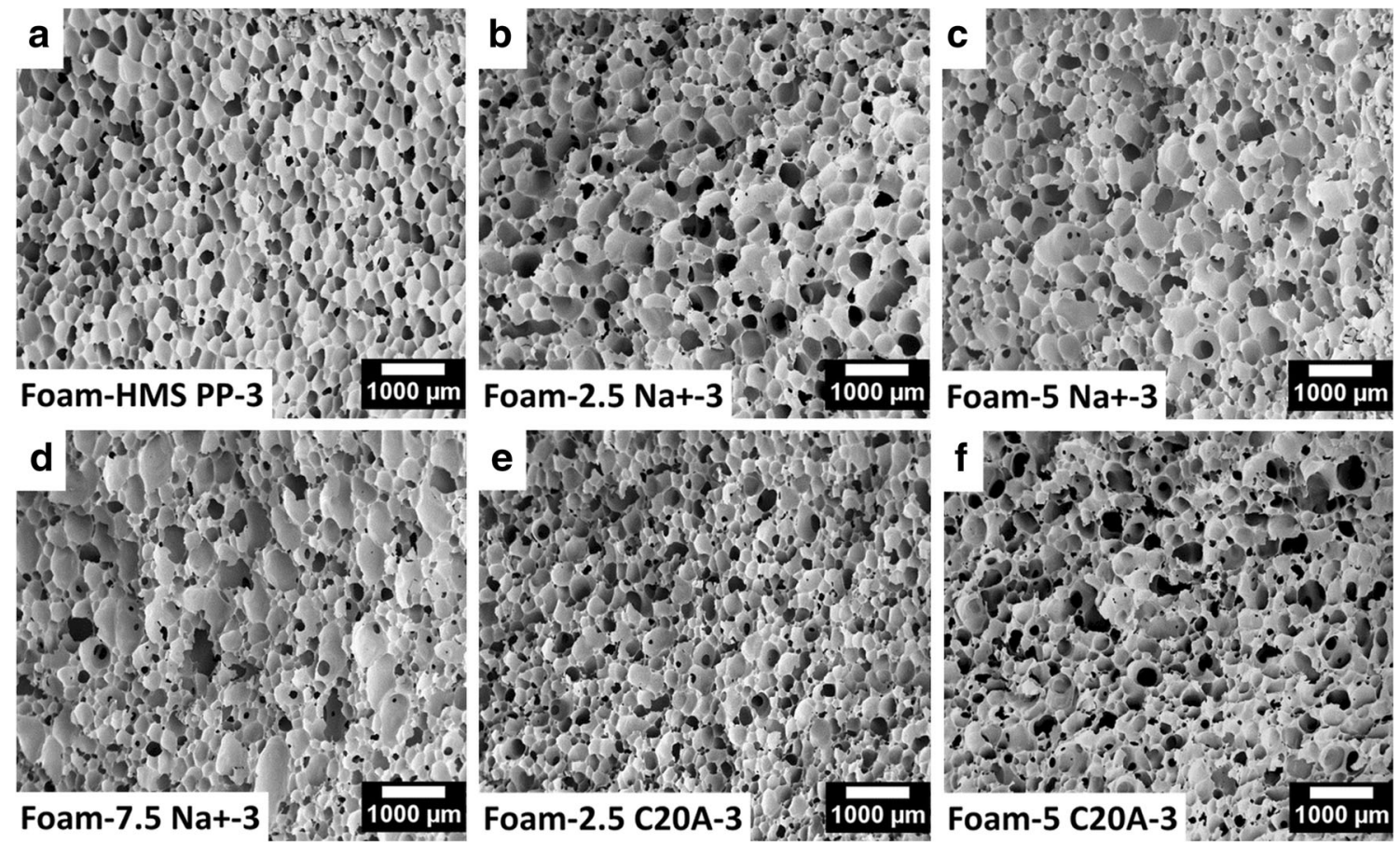

Fig. 7 SEM micrographs of the different cellular materials. a Foam-HMS PP-3. b Foam-2.5 Na+-3. c Foam-5 Na+-3. d Foam-7.5 Na+-3. e Foam-2.5 C20A-3. f Foam-5 C20A-3 
The narrowest cell size distribution is the one corresponding to the pure HMS PP since this is the material with the most homogenous cellular structure. All the cells of this material have sizes lower than $500 \mu \mathrm{m}$. Then, when clays are added to the polymeric matrix the distributions become wider since larger cells appear. Figure 8 also shows the amount of cells with sizes higher than $500 \mu \mathrm{m}$ present in each material. These values are represented in Fig. 9 as a function of the clay content.

In the $\mathrm{Na}+$ composites, approximately $7.5 \%$ of the analyzed cells have sizes larger than $500 \mu \mathrm{m}$ and this value is independent of the clay content. However, in the C20A composites the amount of larger cells increases with the clay content. If this trend is compared to that obtained with the open cell content results, it can be found that both behaviors are very similar. The presence of clay aggregates in the $\mathrm{Na}+$ composites favors the rupture of the cell walls (cell coalescence) leading to higher open cell contents and to larger cell sizes. When the clays are agglomerated, neither the open cell content nor the amount of cells with a size higher than $500 \mu \mathrm{m}$ depend on the clay content. This could be indicating that the $\mathrm{Na}+$ contents employed are not different enough and that higher (or lower) clay contents should be used to detect changes in the open cell content and in the amount of large cells. Nevertheless, when the C20A clays are used, as the intercalation level of these particles is higher, lower clay concentrations are required to detect changes in the open cell content and in the cellular structure. The same phenomena of degeneration which take place in the $\mathrm{Na}+$ composites also occur in the C20A composites. However, in this case the cell wall rupture, with the consequent increase in the cell size, is
Fig. 8 Cell size distribution of the cellular materials produced using the pure HMS PP and the different polypropylene based composites. a Foam-HMS PP-3. b Foam-2.5 Na+-3. c Foam-5 Na+-3. d Foam-7.5 Na+-3. e Foam-2.5 C20A-3. f Foam-5 C20A-3
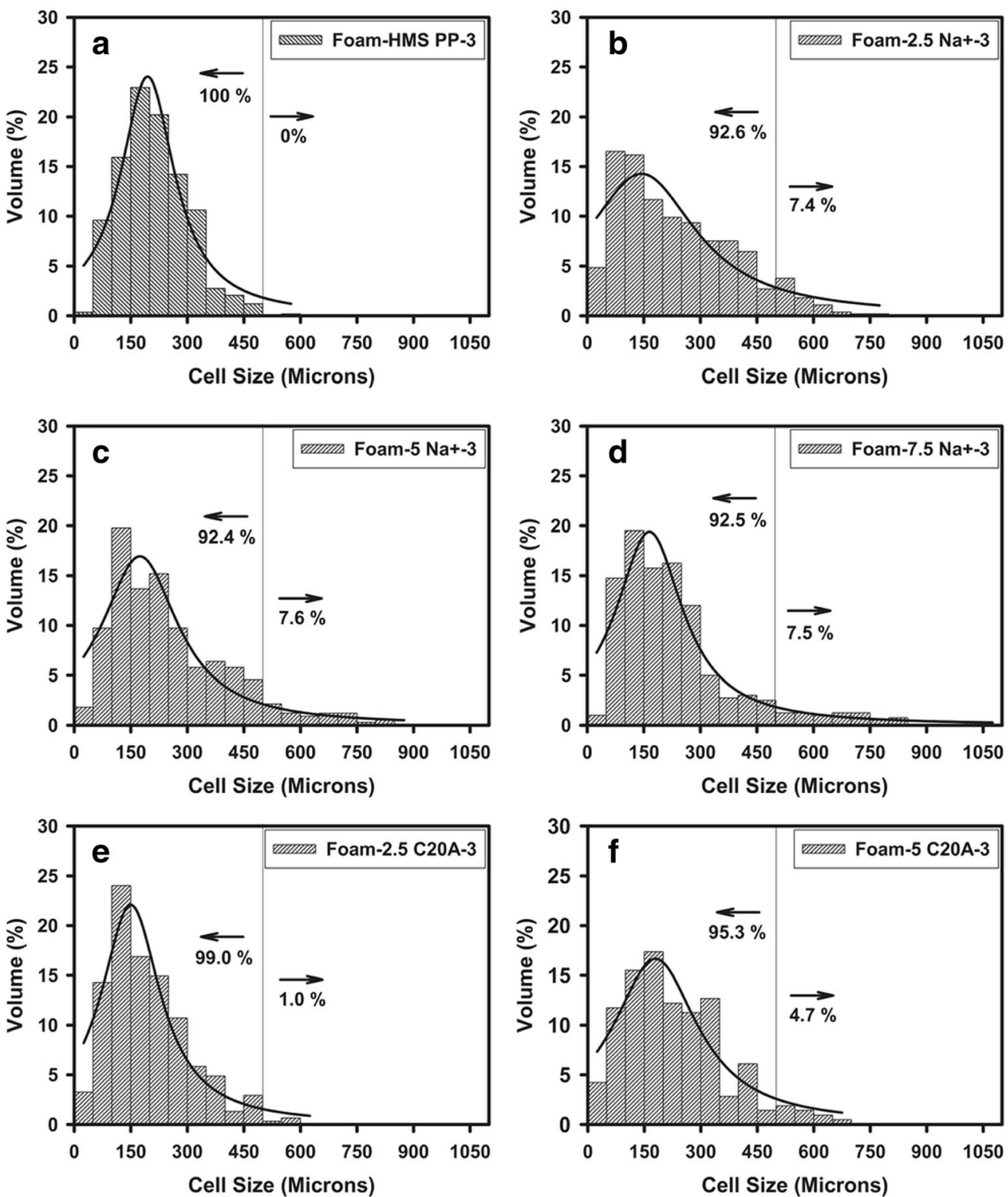


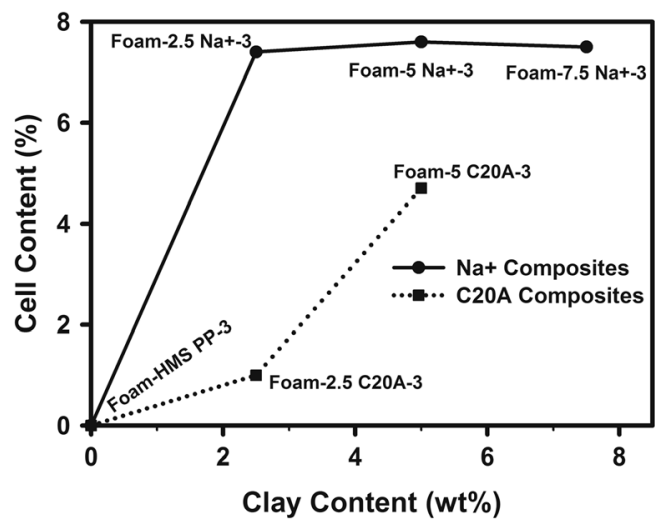

Fig. 9 Cell content with a size higher than $500 \mu \mathrm{m}$ as a function of the clay content

favored by the reduction in $S$ promoted by the addition of organomodified clays.

In order to provide a more accurate description of the cellular structure, several parameters related to the cellular structure have been obtained from the SEM micrographs. Two of these parameters, the average cell size and the cell density, are summarized in Table 4.

As indicated above, when particles are added to the polymeric matrix cells with larger sizes appear and consequently, an increase in the average cell size is produced for most of the analyzed foams (see the values in the Table 4). In connection with the cell density, when the cell size increases the cell density decreases, since cellular materials with the same density are considered. Only the foamed material containing $2.5 \mathrm{wt} \%$ of organomodified clays $(\mathrm{C} 20 \mathrm{~A})$ shows a cell density higher than that of the unfilled foam. In fact, this material shows a cell size distribution similar to that of the pure material although, with a slightly smaller average cell size. The XRD results (Figs. 1 and 2) indicated that this was the material with the highest level of intercalation. An increase in the intercalation level translates into a large number of nucleation points per unit volume. Therefore, it seems that this kind of intercalated structures is favoring the cell nucleation causing the nucleation rate to be higher than the coalescence rate produced by the reduction in $S$. Consequently, the number of cells per cubic centimeter increases and the cell size is reduced. In the other material (Foam-5 C20A-3) in which the clays are less intercalated, the nucleation phenomenon is not as effective as the coalescence phenomenon, which in turn is favored by the low value of $S$.

Finally, a quantitative analysis of the homogeneity of the cellular structure has also been performed by calculating $S D C / \Phi$ (Eq. (3)). In Fig. 10 this coefficient is represented as a function of the clay concentration.

The lowest value of $S D C / \Phi$ corresponds to the cellular material produced with the pure HMS PP. This result confirms qualitative observations as it indicates that the cellular structure of this material is the most homogeneous one. When particles are added to the polymeric matrix an increase in this coefficient is obtained. However, no significant differences are reached in this coefficient by the fact of varying the clay concentration. Figure 10 also reveals that the foams produced with the natural clays present a value of $S D C / \Phi$ slightly higher than that of the foams containing organomodified clays. This indicates that the cellular structure of these materials is more heterogeneous presenting cells with sizes far away from the average value. This also indicates that the phenomenon of degeneration of the cellular structure is more intense in the foams containing natural clays.

\section{Mechanical response}

Mechanical properties in compression were measured for the whole collection of cellular materials produced. As all the materials have very similar densities, the mechanical properties of the considered materials would depend on the one hand, on the mechanical properties of the polymeric matrix and on the other hand, on the morphology and characteristics of the cellular structure.

The solid composites were analyzed by performing tensile test and the experimental results for the tensile modulus are depicted in Fig. 11.

In general, the solid composites containing C20A clays present a tensile modulus slightly higher than that of the composites containing $\mathrm{Na}+$ clays. While an increase of a $10 \%$ with respect to the pure polymeric matrix (HMS PP) is reached by adding $7.5 \mathrm{wt} \%$ of $\mathrm{Na}+$, this value increases up to $14 \%$ in the composite containing $7.5 \mathrm{wt} \%$ of $\mathrm{C} 20 \mathrm{~A}$. The
Table 4 Average cell size and cell density of the different cellular materials

\begin{tabular}{llll}
\hline Sample name & Cell size $(\mu \mathrm{m})$ & Standard deviation $(\mu \mathrm{m})$ & Cell density $\left(\mathrm{cells} \mathrm{cm}^{-3}\right)$ \\
\hline Foam-HMS PP-3 & 212 & 88 & $4.9 \times 10^{5}$ \\
Foam-2.5 Na+-3 & 237 & 153 & $2.8 \times 10^{5}$ \\
Foam-5 Na+-3 & 255 & 158 & $1.7 \times 10^{5}$ \\
Foam-7.5 Na+-3 & 233 & 160 & $2.5 \times 10^{5}$ \\
Foam-2.5 C20A-3 & 195 & 109 & $5.1 \times 10^{5}$ \\
Foam-5 C20A-3 & 230 & 135 & $3.0 \times 10^{5}$ \\
\hline
\end{tabular}




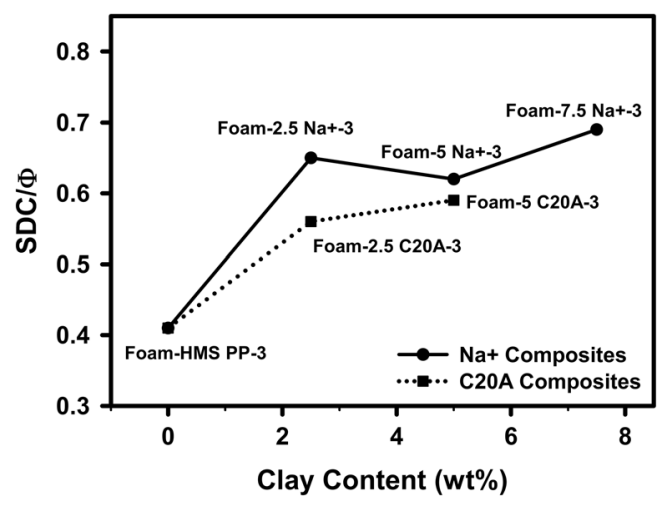

Fig. $10 S D C / \Phi$ for the complete collection of HMS PP based cellular composites

improved performance of the composites containing the organomodified clays could be explained considering that the intercalation degree achieved for these particles is higher than that achieved for the natural clays (Figs. 1 and 2). The composites containing C20A clays also contain a compatibilizer agent and hence, the stress transfer is favored in this system promoting an effective increase in the tensile modulus. However, in the materials containing natural clays the degree of compatibilization between the polymer and the particles is poor and consequently, the stress transmission is also low.

Figure 11 also reveals that, regardless of the type of particles, the tensile modulus increases with the clay content despite of the fact that when the clay content increases the intercalation degree decreases.

Experimental results of the elastic modulus $\left(E_{c m}\right)$ and the collapse stress $\left(\sigma_{c}\right)$, for the foamed materials, are represented in Fig. 12 together with the open cell content values, in order to analyze the influence of this parameter in the mechanical behavior.

The mechanical properties have been related to the open cell content because this is the parameter, connected with the cellular structure, in which more variations have been found

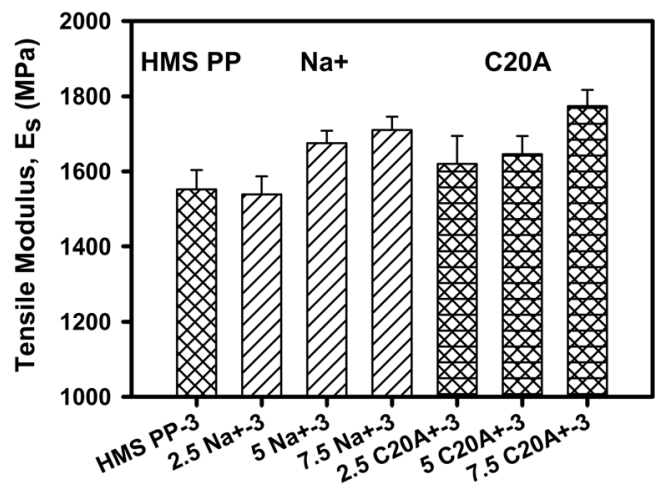

Fig. 11 Experimental results from the tensile tests performed in the solid composites: tensile modulus by the fact of changing both, the clay type and the clay content. Furthermore, the mechanical properties of a cellular material are highly dependent on the open cell content which means that the effects of other parameters like the cell size and the cell homogeneity can be masked by the changes in the open cell content [4]. Figure 12 shows that for a same type of clays both the elastic modulus and the collapse stress follow the same trend.

As the open cell content of the foamed composites containing natural clays is higher than that of the unfilled foam, their mechanical properties are always lower than those of the foam produced with the pure HMS PP (Fig. 12a and b). However, when the clay content increases the mechanical properties also increases despite of the fact that the open cell content was the same for all the composites. To explain this effect, it should be considered that the mechanical properties of the solid composites increase with the clay content and hence, the cell walls are stiffer when a higher amount of clays is used.

In addition, it can be pointed out that the improvements achieved in the foams are greater than those produced in the solid. While an increase of an $11 \%$ is produced in the tensile modulus (measured in the solid composites) when the $\mathrm{Na}+$ content increases from $2.5 \mathrm{wt} \%$ to $7.5 \mathrm{wt} \%$, the elastic modulus of the foamed materials increases by $34 \%$. XRD results showed that a greater intercalation degree was achieved after the foaming process. Therefore, it can be said that despite of the high open cell contents of these materials, the intercalation degrees obtained after the foaming process promote a more effective reinforcement of the polymeric matrix comprising the cell walls. In these materials in which the clays are mainly agglomerated and therefore, the intercalation degrees achieved are poor it is difficult to establish the relationship: rheology-structure-properties since other phenomena which take places simultaneously have to be considered.

In the foams containing C20A clays a direct relationship between the mechanical properties and the open cell content can be established (Fig. 12c and d). An increase in the open cell content involves a decrease in the mechanical properties. Furthermore, the material produced with the pure HMS PP shows the most homogeneous cellular structure which also contributes to improve its mechanical properties. In these foamed materials, despite of obtaining intercalation degrees higher than those reached with the natural clays, the fact of increasing the open cell content could be having a greater effect than the fact of improving the percolated structure giving as a result a deterioration of the mechanical properties. In these materials, in which an intercalated clay structure is obtained, the following relationship could be established: when the clay content increases a decrease in the strain hardening of the polymeric matrix is produced and as a consequence, the quality of the cellular structure decreases and the open cell content of the foamed materials increases, resulting in poorer mechanical properties. 
Fig. 12 Experimental results from compression tests performed in the foamed composites. a Relationship between the elastic modulus and the open cell content for the materials containing natural clays $(\mathrm{Na}+)$. b

Relationship between the collapse stress and the open cell content for the materials containing $\mathrm{Na}+\mathbf{c}$ Relationship between the elastic modulus and the open cell content for the materials containing organomodified clays $(\mathrm{C} 20 \mathrm{~A})$. $\mathbf{d}$ Relationship between the collapse stress and the open cell content for the materials containing $\mathrm{C} 20 \mathrm{~A}$
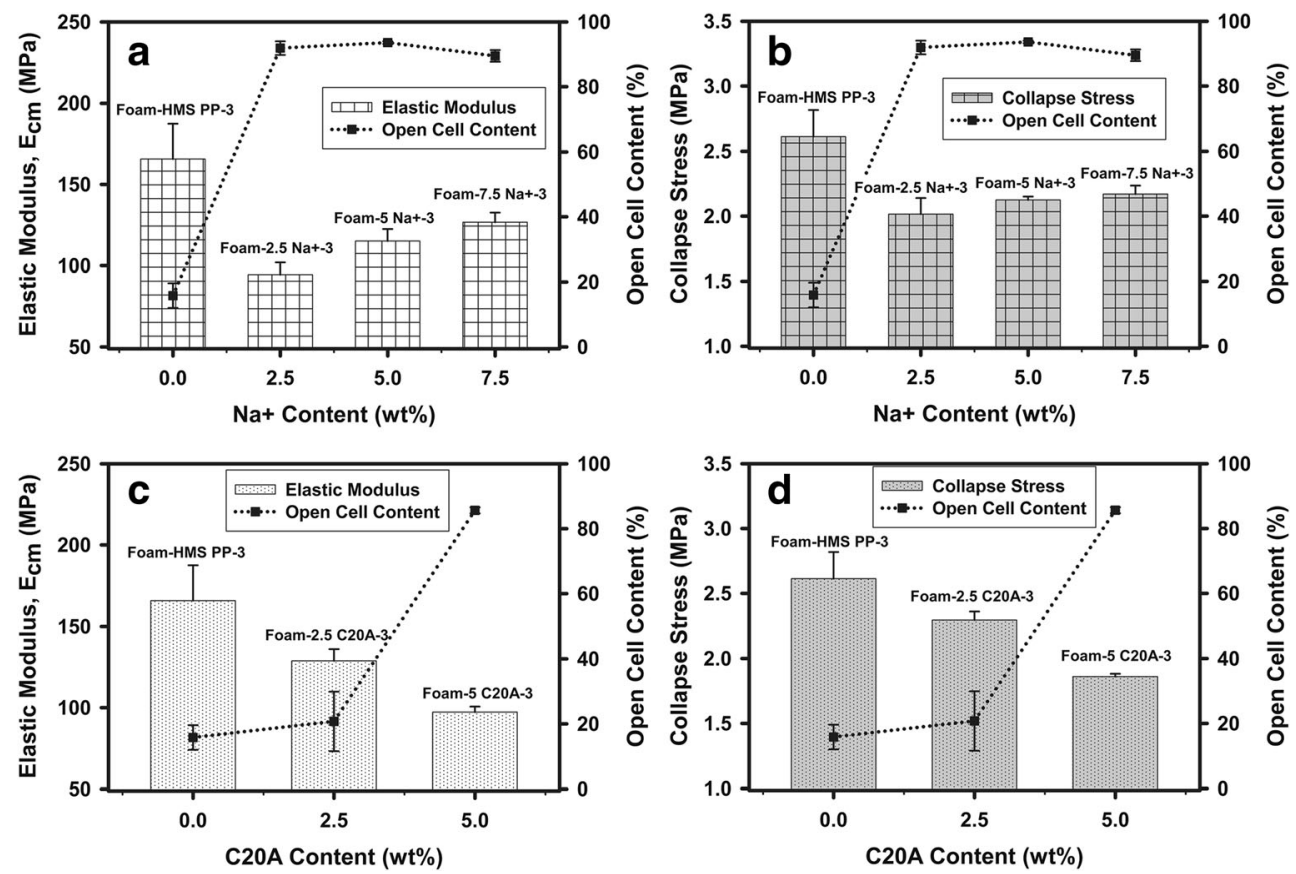

\section{Conclusions}

A detailed characterization of two different types of solid composites and their corresponding foamed materials (produced with the same density) has been performed with the aim of establishing a relationship between extensional rheology, cellular structure and mechanical properties. The first type of composite was produced using natural clays and without a compatibilizer. The second composite was produced using organomodified clays and a compatibilizer (PP-MA). XRD results indicate that the production process (melt compounding) produces on the one hand, an agglomeration of the natural clays and on the other hand, a separation of the clay platelets in the organomodified particles. The extensional rheology results indicate that the strain hardening of the composites containing natural clays is similar to that of the unfilled polymer and it is also independent of the clay content. However, in the composites produced with the organomodified clays, the strain hardening decreases as the clay content increases. As a consequence, the open cell content of the foamed materials containing organomodified clays increases with the clay content. Nevertheless, this behavior is not obtained in the foams produced with the composites containing natural clays. In this case, the composites show an open cell structure opposite to the close cell structure of the unfilled foam. To explain this behavior the size of the particle agglomerates and the cell wall thickness have been measured. Results indicated that there is a considerable amount of agglomerates with a size higher than that of the cell walls and as a consequence, they could be acting as cell openers promoting an increase in the open cell content. In general, the cell size of the cellular materials containing nanoparticles is higher than that of the unfilled cellular materials and their cellular structure is more heterogeneous, except for the material containing $2.5 \mathrm{wt} \%$ of organomodified clays. For this material, the nucleation promoted by the clay particles plays a more important role than the decrease in the strain hardening coefficient. Finally, the mechanical properties have also been analyzed in the foamed and solid composites. Results indicate that a slight increase in the tensile modulus is detected when particles are added to the solid polymeric matrix. In the case of the foamed materials, the mechanical properties of the cellular materials containing organomodified clays decrease as the clay content increases due to the increase obtained in the open cell content. In the case of the cellular materials containing natural clays (with similar open cell contents), their mechanical properties improve as the clay content increases, indicating that the particles are effectively reinforcing the polymeric matrix.

The main conclusion of this work is that, while in the unfilled polymers the extensional rheology is a very useful tool to analyze and understand the cellular structure and mechanical properties of the cellular materials in the filled polymers, the obtaining of this relationship is conditioned by the dispersion level of the layered clays into the polymeric matrix and by the size of the particles used.

Acknowledgements Financial support from PIRTU contract of E. Laguna-Gutierrez by Junta of Castile and Leon (EDU/289/2011) and cofinanced by the European Social Fund is gratefully acknowledged. Cristina Saiz-Arroyo would like to acknowledge Spanish Ministry of Economy and Competitiveness (MINECO) via Torres Quevedo Program (PTQ-12-05504). Finally, financial assistance from MINECO and FEDER program (MAT 2012 - 34901) MINECO, FEDER, UE (MAT2015-69234-R) and the Junta de Castile and Leon (VA035U13) are gratefully acknowledged. 


\section{References}

1. Tripathi D (2002) Practical guide to polypropylene. Rapra Technology Limited, Shrewsbury

2. He C, Costeux S, Wood-Adams P, Dealy JM (2003) Polymer 44: 7181-7188

3. Gotsis AD, Zeevenhoven BLF, Tsenoglou C (2004) J Rheol 48: 895-914

4. Laguna-Gutierrez E, Van Hooghten R, Moldenaers P, RodriguezPerez MA (2015) J Appl Polym Sci 132:42430(1)-42430(14)

5. Gibson LJ, Ashby MF (1997) Cellular solids: structure and properties. Cambridge University Press, Cambridge

6. Fu SY, Feng XQ, Lauke B, Mai YW (2008) Compos Part B-Eng 39:933-961

7. Manias E, Touny A, Wu L, Strawhecker K, Lu B, Chung TC (2001) Chem Mater 13:3516-3523

8. Svoboda P, Zeng C, Wang H, Lee LJ, Tomasko DL (2002) J Appl Polym Sci 85:1562-1570

9. Hasegawa N, Kawasumi M, Kato M, Usuki A, Okada A (1998) J Appl Polym Sci 67:87-92

10. Pavlidou S, Papaspyrides CD (2008) Prog Polym Sci 33: 1119-1198

11. Krump H, Luyt AS, Hudec I (2006) Mater Lett 60:2877-2880

12. Kiliaris P, Papaspyrides CD (2010) Prog Polym Sci 35:902-958

13. Galindo-Rosales FJ, Moldenaers P, Vermant J (2011) Macromol Mater Eng 296:311-340

14. Koo CM, Kym JH, Wang KH, Chung IJ (2005) J Polym Sci Pol Phys 43:158:167

15. Park JU, Kim JL, Kim DH, Ahn KH, Lee SJ, Cho KS (2006) Macromol Res 14:318-323

16. Okamoto M, Nam PH, Maiti P, Kotaka T, Hasegawa N, Usuki A (2001) Nano Lett 1:295-298

17. Mittal V (2014) Polymer nanocomposite foams. CRC Press, Boca Raton

18. Bhattacharya S, Gupta RK, Jollands M, Bhattacharya SN (2009) Polym Eng Sci 49:2070-2084

19. Su FH, Yan JH, Huang HX (2011) J Appl Polym Sci 119:12301238

20. Taki K, Yanagimoto T, Funami E, Okamoto M, Ohshima M (2004) Polym Eng Sci 44:1004-1011

21. Zheng WG, Lee YH, Park CB (2010) J Appl Polym Sci 117:29722979

22. Zhai W, Kuboki T, Wang L, Park CB, Lee EK, Naguib HE (2010) Ind Eng Chem Res 49:9834-9845

23. Alexandre M, Dubois P (2000) Mater Sci Eng 28:1-63

24. Spitalsky Z, Tasis D, Papagelis K, Galiotis C (2010) Prog Polym Sci 35:357-401

25. Zhang Q, Fu Q, Jiang L, Lei Y (2000) Polym Int 49:1561-1564

26. Kim K, Kim H, Lee J (2001) Polym Eng Sci 41:1963-1969

27. Dong Y, Bhattacharyya D (2008) Compos Part A-Appl S 39: 1177-1191

28. Lee SH, Cho E, Youn JR (2007) J Appl Polym Sci 103:3506-3515
29. Kato M, Usuki A, Okada A (1997) J Appl Polym Sci 66: $1781-1785$

30. Lertwimolnun W, Vergnes B (2005) Polymer 46:3462-3471

31. Modesti M, Lorenzetti A, Bon D, Besco S (2005) Polymer 46: 10237-10245

32. Zhai W, Park CB, Kontopoulou M (2011) Ind Eng Chem Res 50: 7282-7289

33. Laguna-Gutierrez E, Van Hooghten R, Moldenaers P, RodriguezPerez MA (2015) J Appl Polym Sci 132:42828(1)-42828(12)

34. Gibson LJ (1989) Mater Sci Eng A-Struct 110:1-36

35. Saiz-Arroyo C, de Saja JA, Velasco JI, Rodriguez-Perez MA (2012) J Mater Sci 47:5680-5692

36. Saiz-Arroyo C, Rodriguez-Perez MA, Velasco JI, de Saja JA (2013) Compos Part B-Eng 48:40-50

37. Saiz-Arroyo C, Rodriguez-Perez MA, Tirado J, Lopez-Gil A, de Saja JA (2013) Polym Int 62:1324-1333

38. Pinto J, Solorzano E, Rodriguez-Perez MA, de Saja JA (2013) J Cell Plast 49:555-575

39. Gong W, Gao J, Jiang M, He L, Yu J, Zhu J (2011) J Appl Polym Sci 122:2907-2914

40. Rodriguez-Perez MA, de Saja JA (1999) Cell Polym 18:1-20

41. Almanza O, Rodriguez-Perez MA, de Saja JA (2001) Polymer 42: 7117-7126

42. Rodriguez-Perez MA, Diez-Gutierrez S, de Saja JA (1998) Polym Eng Sci 38:831-837

43. Perrin-Sarazin F, Ton-That MT, Bureau MN, Denault J (2005) Polymer 46:11624-11634

44. Lee ST (2000) Foam extrusion: principles and practice. Technomic Publishing Company, Lancaster, Pennsylvania

45. Stange J, Uhl C, Münstedt H (2005) J Rheol 49:1059-1079

46. Chaudhary AK, Jayaraman K (2011) Polym Eng Sci 51:1749-1756

47. Dealy JM, Wang J (2013) Melt rheology and its applications in the plastic industry. Springer Science + Business Media, Dordrecht

48. Stange J, Münstedt H (2006) J Cell Plast 42:445-467

49. Takahashi T, Nakajima H, Masubuchi Y, Takimoto J, Koyama K (1998) Sen'i Gakkaishi 54:538-543

50. Takahashi T, Wu W, Toda H, Takimoto J, Akatsuka T, Koyama K (1997) J Non-Newton Fluid 68:259-269

51. Kobayashi M, Takahashi T, Takimoto J, Koyama K (1996) Polymer 37:3745-3747

52. Kobayashi M, Takahashi T, Takimoto J, Koyama K (1995) Polymer 36:3927-3933

53. Le Meins JF, Moldenaers P, Mewis J (2003) Rheol Acta 42: 184-190

54. Naguib HE, Park CB, Panzer U, Reichelt N (2002) Polym Eng Sci 42:1481-1492

55. Rodriguez-Perez MA, Alvarez-Lainez M, de Saja JA (2009) J Appl Polym Sci 114:1176-1186

56. Lee LJ, Zeng C, Cao X, Han H, Shen J, Xu G (2005) Compos Sci Technol 65:2344-2363

57. Lee ST, Park CB, Ramesh NS (2007) Polymeric foams: science and technology. CRC Press, Boca Raton 